\title{
العوامل المؤروة على استقلالية وموضوعية التدقيق الداخلي دراسة ميدانية على واقع المؤسسات الحكومية في كرميان
}

\author{
سوران محمد امين \\ جامعة بوليتكنيك سليمانية/معهد التقني كلار/قسم الخاسبة \\ E-mail:soran.habeeb@spu.edu.iq \\ ORCID: 0000-0001-6291-8464 \\ الاسم : سوران محمد امين حبيب/جامعة بوليتكنيك سليمانية/معهد تقني كلار/قسم محاسبة ماجستير محاسبة/مدرس مساعد/ \\ رئيس قسم الخاسبة. \\ منشورات: مدى كفاءة المراجعة الخارجية للحد من ممارسات الخاسبة الابداعية/ I ـ ب/مؤتم العلمي جامعة جيهان.
}

\section{هونه ر محمد محمد امين}

جامعة بولينكنيك سليمانية/ معهد تقني دربنديخان /قسم الخحاسبة

E-mail:honar.mohammed@spu.edu.iq

ORCID:0000-0003-3739-2880

الاسم : هونه ر محمد محمد امين /جامعة بوليتكنيك سليمانية /معهد تقني دربنديخان/قسم محاسبة .

ماجستير محاسبة/مدرس مساعد/ محاظر في قسم الخاسبة.

منشورات: مدى كفاءة المراجعة الخارجية للحد من ممارسات الخحاسبة الابداعية/Y IV ـ أمؤتمر العلمي جامعة جيهان.

يُّشكهوت عبدالله عبدالكريم

جامعة بوليتكنيك سليمانية/معهد التقني كلار/قسم الخاسبة

E-mail:peshkawt.abdullah@garmian.edu.krd

$$
\begin{aligned}
& \text { ORCID:0000-0001-5177-9104 } \\
& \text { الاسم : بيشكهوت عبدالله عبد الكريم/جامعة گهرميان } \\
& \text { ماجستير محاسبة/مدرس مساعد /مدير حسابات/محاظر في معهد تقني كلار/جامعة جيهان. }
\end{aligned}
$$




\title{
الملخص:
}

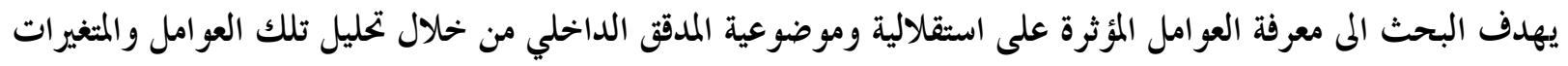
المكونة لهاإلى جانب استطلاع رأي مجتمع البحث حول مدى توفر تلك العوامل لدى المدققين الداخليين في المؤسسات الحككومية في إدارة كرميان, وقد توصل البحث إلى العديد من النتائج أهمها مايأتي:

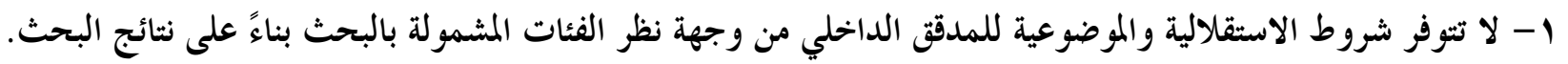

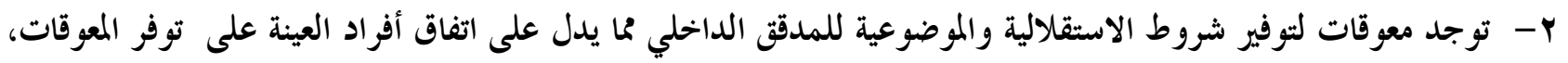
لتوفر شروط الاستقلالية والموضوعية للمدقق الداخلي. ب- تسود في معظم الحالات المنافسة بين الخاسبين للعمل كمدقق داخلي مما يؤدي إلى دعم الإادارة في فرض هيمنتها على تروصيه المدققين الداخليين.

ع- لا يتم توفير فريق عمل متخصص من المدققين الداخليين مُن تتوفر فيهم المهارة والمعرفة والتخصص التي تمكنهم من أداء أعمالهم بصورة مستقلة وموضوعية. وقد خلص البحث الم مجموعة من التوصيات أهمها:

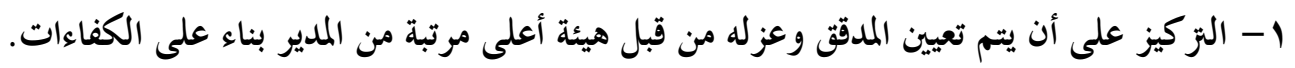
ب- الاهتمام بوضع أطر خاصة كامتحان للمنافسة على منصب المدقق الداخلي. ب- إجبار إدارات المؤسسات على عدم فرض قيود على نطاق عملية الثدقيق الداخلي والتعامل بجدية مع تقارير التدقيق الدورية.

\begin{abstract}
:
The Research aims at identifying the factors that affect the Independence and Objectivity of the Internal Auditor by Analyzing the Factors and the variables that constitute them, in addition to surveying the society of the study on the availability of these factors among the internal auditors in the government institutions of the Garmain administration.
\end{abstract}

\section{Study findings:}

1 - The conditions of independence and objectivity of the internal auditor are not available from the point of view of the categories covered by the research based on the results of the research.

2 - There are obstacles to provide the conditions of independence and objectivity of the internal auditor, which indicates the agreement of the sample members on the availability of constraints to provide the conditions of independence and objectivity of the internal auditor.

3. In most cases, there is competition among the accountants to act as an internal auditor, leading to the administration's support in imposing its hegemony on the internal auditors.

4. A specialized team of internal auditors who have the skills, knowledge and specialization to enable them to perform their work independently and objectively is not provided. 


\section{Study recommendations:}

1 - Focus on the appointment of the auditor by a higher body of the Director based on competencies.

2 - Work to be isolated internal auditor by a higher body of the Director to prevent it from affecting the independence and objectivity.

3 - Interest in the development of special frameworks as an exam to compete for the position of internal auditor.

4. To force the management of institutions not to impose restrictions on the scope of the internal audit.

مقدمة:

يتم انجاز عمليات الثدقيق الداخلي في بيئات متنوعة وضمن مؤسسات مختلفة من حيث الغرض والحجم والهيكل, وعلاوة على ذلك فإن القوانين واللوائح ضمن البلدان المتعددة تختلف من بلد المى أخر , وبشكل خاص يواجه مدققي القطاع العام تحديات العمل في هياكل تنظيمية معقدة ومختلفة, شأنها شان الاشكال العديدة للحكومات التي تتواجد على امتداد العالم اليوم. ويشتزط فيمن يمارس التدقيق الداخلي أن يكون على قدر عال من الكفاءة، وأن يتصف بالموضوعية والاستقلالية، وأن يكون على معرفة بما يحصل من تطورات في مجال عمل التدقيق الداخلي، لكي لا تبقى وحدات التدقيق الداخلي بعيدة عن تلك النطورات.

ولقد نال موضوع استقلالية وموضوعية المدقق الداخلي اهتماما كبيرا في اقليم كردستان من قبل الباحثين اذ تتمثل مسؤولية المدقق الداخلي في التخطيط والتنفيذ لعملية التدقيق, للحصول على توكيد منطقي فيما إذا كانت القوائم المالية خالية من التحريف بسبب الغش أو الخطأ, كما إنً على المدقق الداخلي أن يأخذ في الاعتبار أي عامل قد يؤثر على استقلاليته وموضوعيته بصورة سلبية عند تنفيذ المهمة الموكلة إليه. فالاستقلال والموضوعية هما الأكثر أهمية بالنسبة لمدقق الحسابات.

$$
\text { وتم تناول الموضوع من خلال : }
$$

1- المبحث الاول: منهجية البحث وعدد من الدراسات السابقة.

r- المبحث الثاني: الاطار النظري.

ب- المبحث الثالث: الدراسة الميدانية.

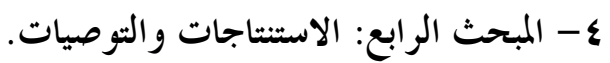




\section{المبحث الأول}

\section{منهجية البحث والدراسات السابقة}

أولاً: اهمية البحث:

إنً من المهامات الأساسية للتدقيق الداخلي هو ضمان سلامة التصرفات المالية من قبل الوحدات الحكومية بمجملها للتأكد من سلامة الإجراءات المالية قبل الصرف وهذا يضمن الحفاظ على المال العام وحمايته من التلاعب أو الهدر أو الحد من عدم اعتماد الصيغ المالية السليمة وفقا للتعليمات النافذة. وبالتالي فإن ضمان استقلالية وموضوعية المدقق الداخلي سوف تزيد من كفاءة عملية التدقيق, الأمر الذي ينعكس على الكثير من الأنشطة داخل الوحدة.

\section{ثانياً: مشكلة البحث:}

يجب أن يكون لدى نشاط التدقيق الداخلي تفويض صريح ومكتوب في ميثاق التدقيق الداخلي والذي يبين الغرض من نشاط التدقيق الداخلي، وتوضيح صلاحيات ومسؤوليات النشاط بهدف تعزيز الاستقلالية والموضوعية داخل المؤسسة. ويكون

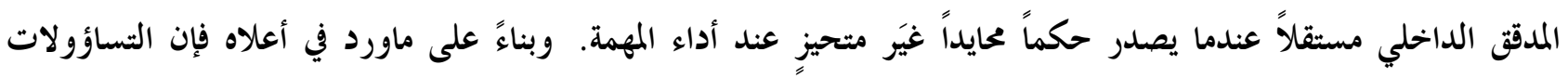
لمشكلة البحث تتمثل في : 1 ـ . هل ثمة شروط استقلالية وموضوعية للمدقق الداخلي في مؤسسات عينة البحث؟

r. ما هي أهم المعوقات لتوفير شروط الاستقلالية والموضوعية للمدقق الداخلي من وجهة نظر عينة البحث؟

ثالهاً: فرضيات البحث: في ضوء تساؤلات مشكلة البحث تتمثل فرضيات البحث فيما يأتي: ا. لا تتوفر شروط الاستقلالية والموضوعية للمدقق الداخلي في مؤسسات إدارة كَرميان. ץ. . ل ا تو جد معوقات لتوفير شروط الاستقلالية والموضوعية للمدقق الداخلي في مؤسسات إدارة كَرميان. رابعاً: اهداف البحث: إنّ المدف اللئيس للبحث هو التحقق من الفرضيات السابق ذكرها, والتوصل إلى نتائج معينة بشان التساؤلات في إطار مشكلة البحث ويمكن تحقيق ذلك من خلال تقسيم أهداف البحث إلى القسمين الرئيسين التاليين: ا. تسليط الضوء على اهمية توفر شروط الاستقلالية والموضوعية للمدقق الداخلي وعلى القواعد والتعليمات الخاصة بالاستقلالية والموضوعية والمنصوص عليها في التعليمات والقوانين. Y. التحقق من مدى توفر شروط الاستقلالية في الممارسات المهنية الفعلية وذلك من وجهة نظر بحيع الفئات ذات العلاقة والوقوف على أراء الفئات المشمولة بالبحث بخصوص المعوقات التي قد تحول دون توفر شروط الاستقلالية. 
r. . التحقق من عدم وجود معوقات لتوفيز شروط الاستقلالية والموضوعية للمدقق الداخلي في مؤسسات ادارة كرميان.

خامساً: التعريفات الإجرائة:

ا - الثدقيق: هو عملية منظمة ومنهجية, إذ تتضمن مجموعة من الإجراءات المتتابعة والمخططة يقوم بها المدقق استناداً إلى الأهداف والمعايير المتفق عليها.

ץ- الاستقلال: بمعنى استقلال المدقت مهنياً من خلال عدم وجود أية ضغوط أو تدخل من جانب إدارة المؤسسة في الدور الذي يقوم به المدقق بشأن التحقق من سلامة الدفاتر ودقة تمثيل القوائم المالية لنتائج الأعمال والمركز المالي للمشروع.

ب- الموضوعية: هي حالة ذهنية غير متحيزة تسمح للمدقين الداخليين لأداء المهام على نحو يجعلهم مقتنعين بنتائج أعمالهم وعدم التأثير على جودتها.

سادساً: الدراسات السابقة: ا - أحد محمد غنيم الرشيدي (Y ( • Y): ملى توافر شروط الاستقلالية لمدقي الحسابات المارجيين في دولة الكويت: دراسة مقارنة:

هدفت الدراسة المى التعرف على مدى توفر شروط الاستقلالية لمدققي الحسابات الخارجيين في دولة الكويت, وتوصل الدراسة إلى أنه لا تتوفر شروط الاستقلالية لمدقتي الحسابات الحارجيين في دولة الكويت من وجهة نظر الفئات المشمولة

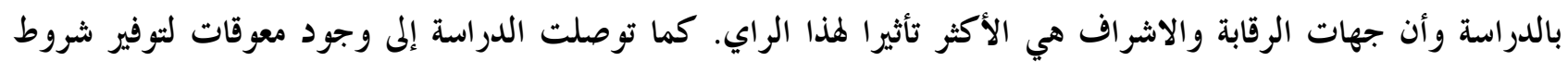
الاستقلالية لمدققي الحسابات الخارجيين في دولة الكويت. ץ- محمد اسامة (V + . Y): العوامل المؤثرة على استقلالية وحياد المراجع الخارجي (دراسة تطبقية ميدانية على المراجعين القانونين في قطاع غزة ــلسطين)

هدفت الدراسة إلى توضيح العو امل المؤثرة على استقلال وحياد المراجع الخارجي من خلال تحليل تلك العو امل والمتغيرات المكونة لها, وتوصل الدراسة إلى أن تقديم المدقق للخدمات الاستشارية إلى جانب خدمات التدقيق في نفس الوقت سوف يلى يؤثر بشكل

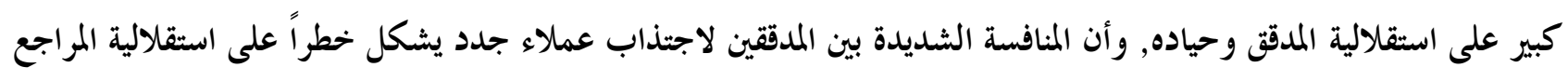
وبالتالي كفاءة عملية التدقيق.

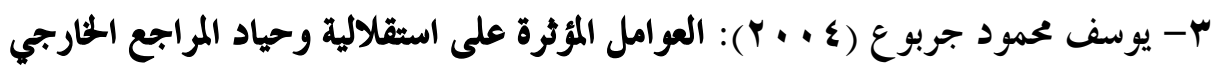

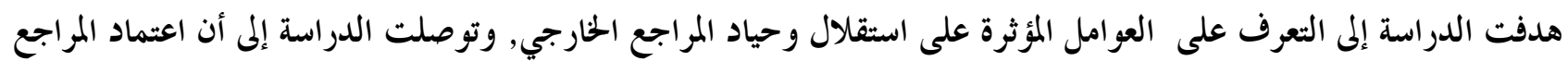
الخارجي على زبون واحد يهدد استقلاله وحياده ولا سيما مكاتب المراجعة الصغيرة التى تكون مملو كة لمراجع واحد. كما وأن 
تعرض المراجع الخارجي لبعض الضغوط من قبل إدارة المنشأة عن طريق التعيين وتحديد الاتعاب والعزل إذا لم يقم المراجع بتنفيذ رغبات الإدارة ومطالبها والسير في ركابها.

\section{المبحث الثاني: الإطار النظري \\ ماهية التدقيق الداخلي}

التمهيد:

ظهرت مهنة التدقيق الداخلي بشكل متواز مع تطور علم الادارة بعد الحرب العالمية الثانية وهو أحسد الوسـائل الفعالـة للرقابـة

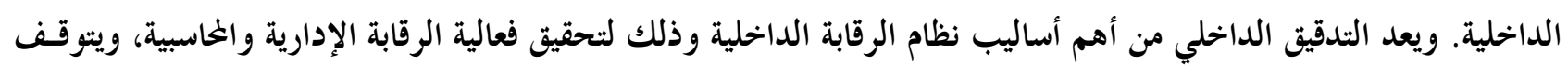

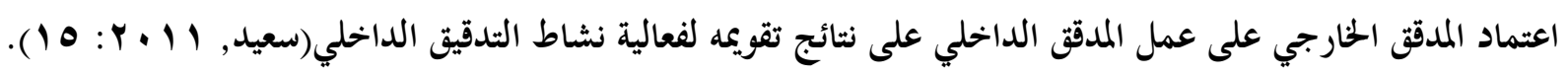
اولاً: مفهوم التدقيق الداخلي: تمارس وظيفة التدقيق الداخلي دوراً مهماً في توجيه عمليات الوحدة الاقتصادية نحو النجاح إذ تساعد في فحص وتقييم الأنشطة المالية والإدارية والتشغيلية وتزويد الإدارة على المستويات كلها بالمعلومات اللازمة للمساعدة في تحقيق الضبط والحماية

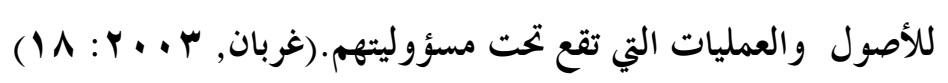

وقد عرّفَ معهد المعايير الدولية للممارسة المهنية للتدقيق الداخلي التدقيق الداخلي بأنه: "نشاط مستقل, موضوعي واستشاري, مصمّم" ليزيد من قيمة الشركة, وتحسين عملياتها, ويساعد التدقيق الداخلي في تحقيق أهدافها من خحلال منهجية

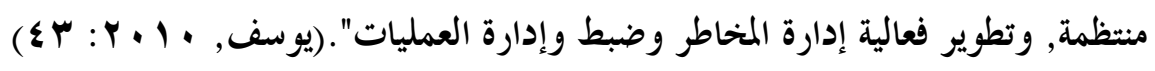
وكما يعرف على أنه "جهاز تقويمي مستقل ضمن تشكيلات الوحدة الاقتصادية ويُعد أحد وسائل الرقابة الداخلية الفعالة تنشئه الادارة للقيام بخدمتها وطمأنتها على أن وسائل الضبط الموضوعة مطبقة وكافية بوساطة مجموعة من الضو ابط والاجوراءوات

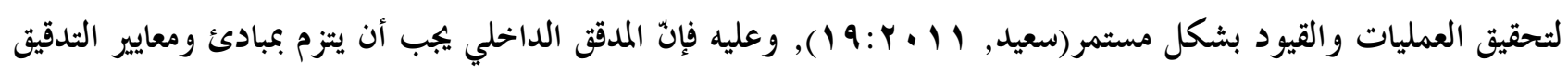
الداخلي الذي يضمن استقلاليته وموضوعيته.

\section{ثنانياً: نشأة وتطور التدقيق الداخلي:}

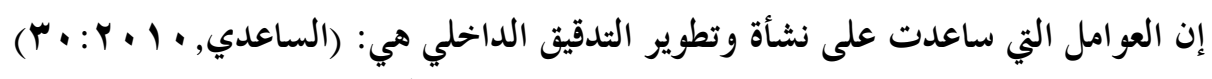

$$
\begin{aligned}
& \text { 1- - ظهور الوحدات الاقتصادية ذات الفروع المنتشرة جغر افياً. } \\
& \text { r- الحاجة إلى وسائل لاكتشاف الخطأ و الغش. } \\
& \text { ب- ظهور المصارف وشر كات التامين. }
\end{aligned}
$$

ع - اهتمام الإدارة بنتائج الأداء أولاً بأول والعمـل على متابعتهـا وذلـك نظـراً لتعقــ العمليـات الإنتاجيـة وتطـور الأسـاليب

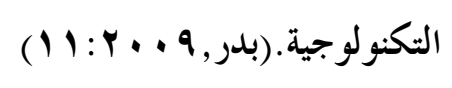


ه- - الاستقلال التظيمي للإدارات ضمن الهيكل التنظيمي و تعدد المسـتويات الأداريسة في المنشـأة، فقـد اضـطرت الإدارة إلى تفويض السلطات والمسؤوليات.

\section{كالكاً: أهداف التدقيق الداخلي: يهدف التدقيق الداخلي إلى جملة أمور هي:}

ا- الغحافظة على اموال الوحدة (بالنسبة للايرادات والمصروفات) من خلال بيان صحة الاجراءات المالية من بدايتها وانتهاءا

باجر اءات التزحيل والمطابقة والفحص(بدر , 9 ـ . ץ: 11 ).

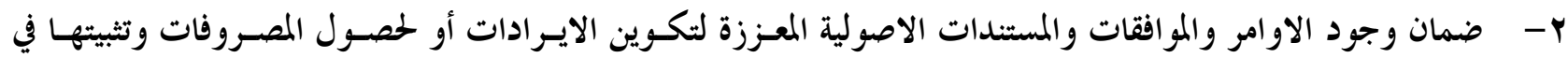
سجلات الوحدة الاقتصادية على أن تكون متماشية مع القوانين والتعليمات النافذة.

ب- تأكيد على قيام الموظفين المختصين بواجباتهم على اكمل وجه من دون هدر أو ضياع في اموال الوحسدة لتحقيسق اقصى

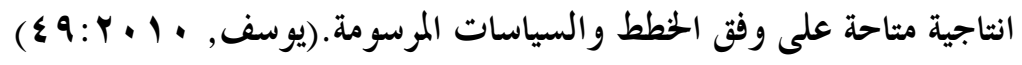

ع - التقرير بان ما يتم من اجراءات في ضمن هذا الجال يقع في الاطار القانوني الخحد له من المسؤوليات والصلاحيات، وانسه لايوجد خرق في هذا الجانب.

ه- التحقق من مطابقة الواقع العملي لما ورد في خطط الوحدة الاقتصادية وان الانحر افات أن وجدت فهي معروفـة ومحسددة ومسيطر عليها أو يمكن دراستها وتقويمها لمعالجنتها وتلافيها مستقبلا.

צ- أن متابعة الاداء وتقويم الفاعليات والحكم بشكله النهائي والتوصسية بـالحلول إلى الادارة العليـا يجـري بمطلـق الحياديـة

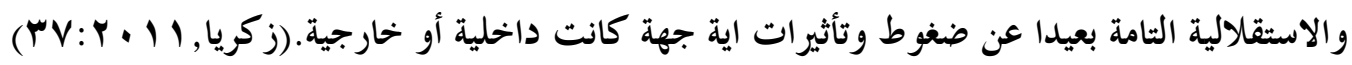

\section{رابعاً: أنواع التدقيق الداخلي:}

يمارس المدققون الداخليون انواعا عدة من التدقيق في الوحدات التي يعلمون فيها وهي:

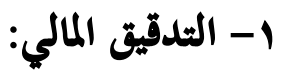

ويقصد به تحليل النشاط الاقتصادي للوحدة الاقتصادية وتقييم الانظمة الخاسبية وانظمـة المعلومـات والتقـارير الماليـة

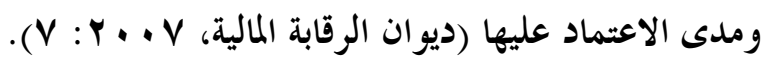

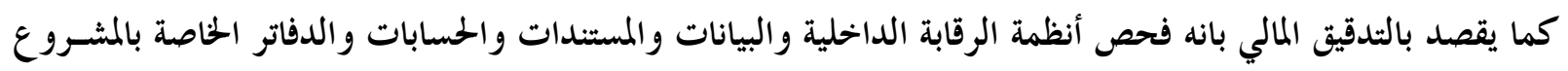

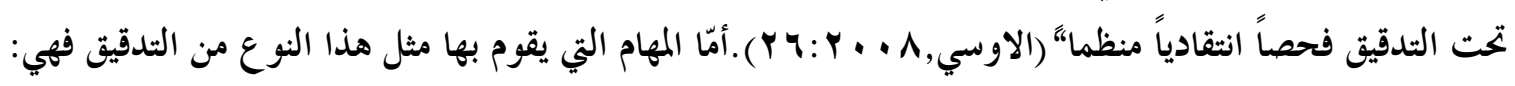
أ- التأكد من صحة وعدالة البيانات المالية. 


\section{ب-التأكد من تخفيض تكاليف التدقيق الخارجي. \\ ج- التحقق من إتمام العمليات المالية بطريقة صحيحة. \\ د- التحقق من مسؤولية مدراء المالية.

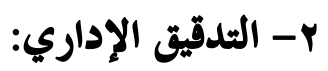

عبارة عن مراجعة الضوابط المالية وضوابط الأنشطة, وما له من علاقة بالقوانين والتنظيمات، لتحديد مـدى الالتـزام

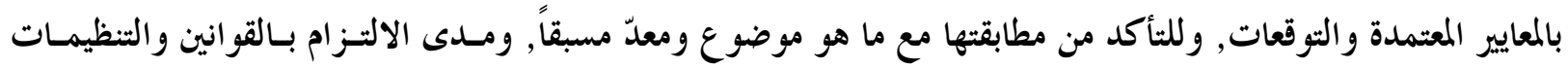

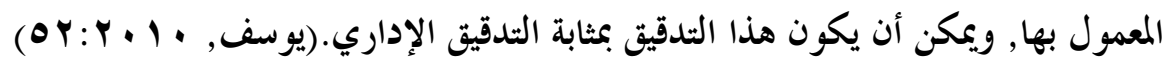

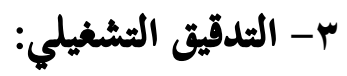

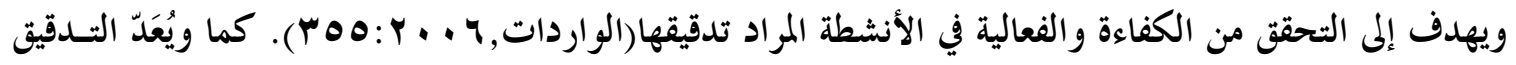
الداخلي التشغيلي على أنه الفحص والتقييم الثـامل لعمليـات المثـروع، لغـرض إعـلام الإدارة بمـا إذا كانـت العمليـات

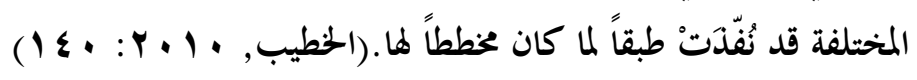

\section{خامساً: استقلالية وموضوعية المدقق الداخلي:}

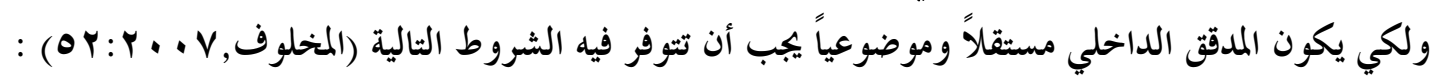
ا- يجب أن ترتفع المكانة التظيمية للمدقق الداخلي وأن يتبع الإدارة العليا، وأن يتحرر من أية رقابة إثرافية، أو من أي تأثير من الإدارة في أي مجال يخضع للتدقيق. ץ- يجب أن يحظى المدقق الداخلي بالتأييد الكامل من الإدارة في كل القطاعات. ويتضمن ذلك وضع دستور وظيفة التدقيق الداخلي الذي يتضمن تحديداً واضحاً ورسمياً لأهداف وظيفة التدقيق الداخلي وسلطاتها ومسئولياتها والوضع التنظيمي للمدقق الداخلي، ونطاق وظيفة التدقيق الداخلي. ب- يجب أن يكون تعيين رئيس إدارة التدقيق الداخلي وعزله من اختصاص المدير العام أو لجنة التدقيق. ع- يجب أن يتمتع المدقق الداخلي بالاستقلال الذهني، وأن يكون قادراً على صنع الأحكام وإبداء الرأي دون تحيز. ه- يجب أن يتحرر المدققون الداخليون من التأثيرات غير الضرورية التي يمكن أن تؤثر جوهرياً على نطاق عملهم و الأحكام أو الأداء الذي ينتج من تقرير التدقيق. צ- إن أهمية استقلال المدقق ترتبط بالموضوعية التي يتمتع بها وتجنب تعارض المصالح والوضع التظيمي للمدقق الداخلي. 


\section{سادساً: معايير الثدقيق الداخلي الدولية الصادرة عن معهد المدققين الداخليين:}

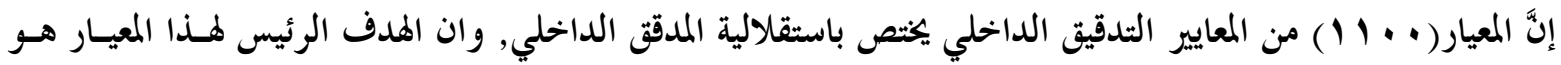

الحفاظ على استقلالية وحدة التدقيق الداخلي عن الأنشطة التي تتولى عملية تدقيقها حتى يتحقق للوحدة التـدقيق الـداخلي أداء

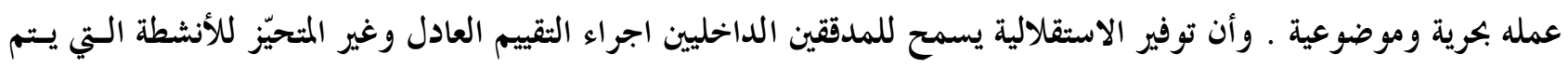

تدقيقها. ويتضمن هذا المعيار جانبين رئيسين هما: .(عبد ربه, • 1 • ؟: ؛ ه)

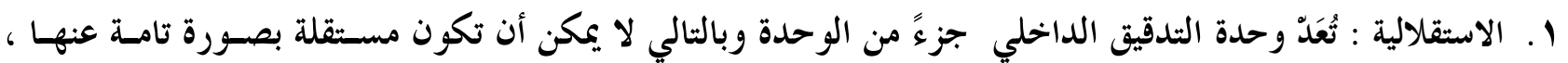
ويجب أن ترتبط وحدة التدقيق الداخلي بأعلى مستوى إداري في المؤسسـة ، مـن أجسل أن يتسيح لهـا ذلك فرصـــ

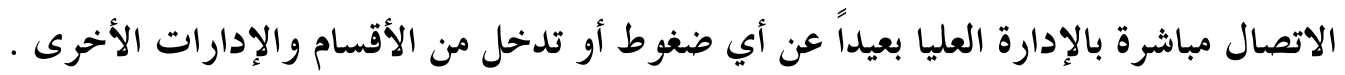

r. الموضوعية : يجب ان تكون وحدة الثدقيق الداخلي موضوعياً في ادائها للعمليـات الحخاصـة بالتـدقيق ، أي تسـتخدم الحياد التام والمنطق عند ادائها لمهام التدقيق ، وأن لا يتأثر حكمها في قضايا التدقيق بآراء الغير ، وتتحقق الموضوعية من خحلال تحديد اختصاصات العاملين في وحدة التدقيق الداخلي، وتغيير وتبديل المهام الموكلة لأعضاءها مسن وقـت المى آخر ، وعدم السماح لمم بالقيام بمهام وأعمال تخص إدارات أو أقسـام أخــى ، والتحقـق مـن نتسائج التـدقيق الداخلي قبل كتابة التقارير.

\section{سابعاً: العوامل المؤثرة في استقلالية وموضوعية الثدقيق الداخلي:}

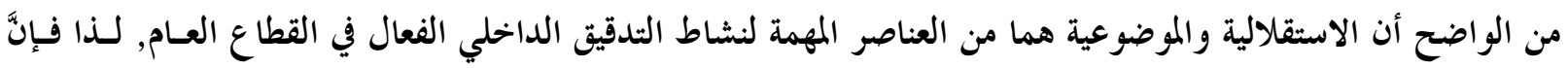

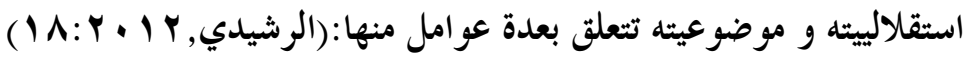

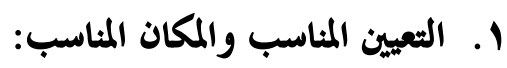

إن القدرة على تحقيق الاستقلالية وموضوعية نشاط التدقيق الداخلي تتوقف على التعسيين المناسـب و المكانـة التنظيميـة

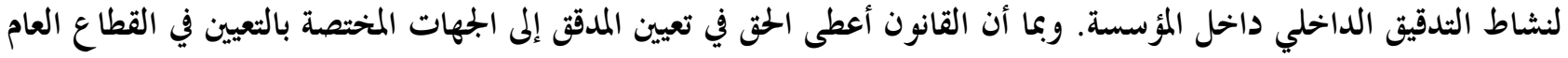

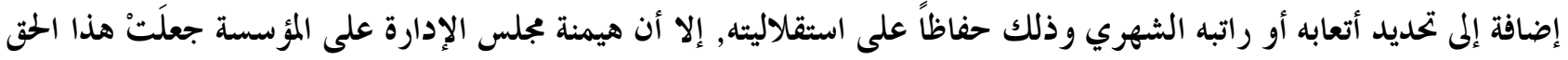
غير ذي جدوى وجعلت استقلالية المدقق عُرضةً للشك.

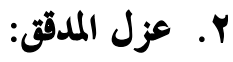

في كثير من الأحيان وكما هو الحال بالنسبة لتعيين المدقق يهيمن مجلس إدارة المؤسسة (مدير المؤسسة) على قرار عزل المسدقق

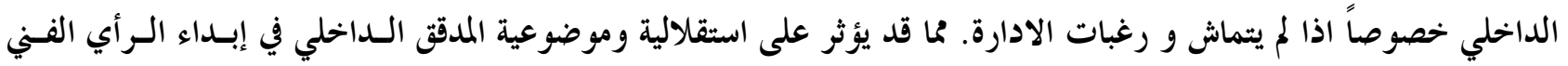


ويقصد به ارتباط مالي مباشر وغير مباشر, فالمباشر أي أن تكون العلاقة ثنائية بين المدقق وإدارة وموظفي المؤسسة. كأن يدخل في علاقة تجارية مشتز كة او قد يكون على شكل وعد بالحصول على منحة أو مصلحة مالية للمؤسسة. أما غير المباشر أي أنْ تكون هناك علاقة مالية بين زوجة المدقق مثلاً, أو أحد أقاربه من الدرجة الأولم. وبين اصحاب المابل القرار اوالعاملين في المؤسسة من خحلال علاقة تجارية مباشرة. ع. المدايا والهبات:

أن تلقى المدقق الداخلي أو أحد افراد أسرته الهدايا من الموظفين العاملين أو أفر اد إدارة أو مدير المؤسسة وهـذا يـؤثر سـلبًا على استقلاليته وموضوعيته, ويجعله تحت تأثير الإدارة مما يدفعه إلى تحقيق توجهاتهم في تقريره, مخالفا بذلك مبدأ الاستقلالية.

\section{๑. طول فترة ارتباط المدقق الداخلي بالمؤسسة:}

يحدث في كثير من الاأحيان أن يتولى المدقق الداخلي مهمة تدقيق حسابات المؤسسة لعدة مرات خحلال فنزات زمنية متعددة,

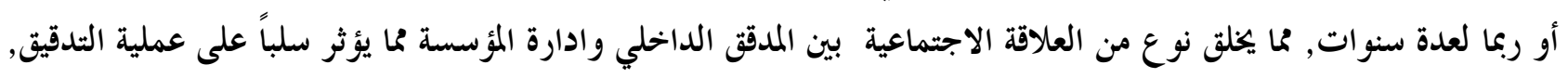
واستقلالية المدقق.

\section{المبحث الثالث: الدراسة الميدانية \\ المطلب الاول:حدود البحث وصعوباته}

\section{1-حدود البحث:}

تتمثل حدود هذا البحث فيما يأتي:

أ- الحدود المكانية: الغرض من البحث هو التعرف على العوامل المؤثرة على استقلالية وموضوعية المدقق الداخلي- دراسة ميدانية في إدارة كُريان. لذا انحصر البحث في حدود قضاء كلار مركز إدارة كرميان, بغرض الحصول على أكبر عينة مُكنة.

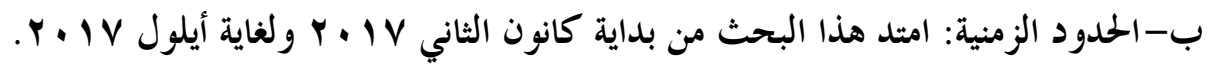
ج- الحدود البشرية: شمل هذا البحث أكاديميين ومهنيين أصحاب شهادات علمية في مجال الخاسبة والتدقيق, أو أصحاب خبرة مهنية في الجمال نفسه.

د- الحدود الموضوعية: اهتم هذا البحث بمحورين رئيسين مرتبطة بفرضيات البحث, ومدى إمكانية مواءمتها مع الواقع في إدارة كرميان. 


\section{Y - صعوبات البحث:}

رغم أهمية الموضوع وسعي الباحثين لتحصيل نتائج موضوعية, إلا ألّ البحث لم تخل ُمن بعض الصعوبات ويمكن توضيح أهمها على النحو الآتي:

أ- عدم معرفة أغلب أفراد عينة البحث باللغة العربية, مما اضطر الباحثون إلى ترجمة استمارة الاستبيان إلى اللغة الكردية.

$$
\text { ب- حداثة الموضوع, وصعوبة الحصول على أفراد لهم اطلاع جيد عليه. }
$$

ج- كان على الباحثين إشراك جميع أفراد العينة في قسم الخاسبة والتدقيق, مما اضطر الباحثون إلى تنقل بين المؤسسات الحكومية في مركز إدارة كرميان.

\section{المطلب الثاني \\ الطريقة والاجراءات}

يتناول هذا المبحث تصميم البحث والإجراءات التي تستخدم فيه والتي تتضمن وصـفاً لمفـردات البحسث وطـرق المعاينسة وثبات أداتها وإجر اءات تصميمها وبمع بياناتها والمعالجات الاحصائية المستخدمة. أولاً:منهج البحث:

يقوم البحث على المنهج الوصفي التحليلي لتحقيق أهداف البحث. ثانياً: مجتمع العينة البحث :

يتكون مجتمع البحث من الخاسبين والمدققين في ادارة كرميان, الا ان عينة البحث تم تحديدها في الدوائر التابعة لوزارة المالية في ادارة كرميان (مليرية خزينة كرميان, بنك كلار, بنك شيروانة, مديرية ضريبة دخل كرميان, مديرية ضريبة عقار كرميان,

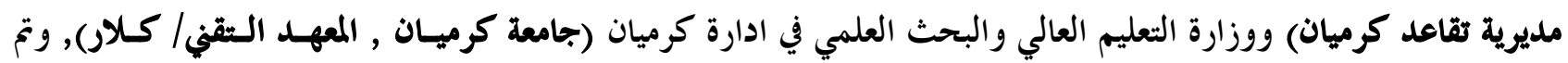

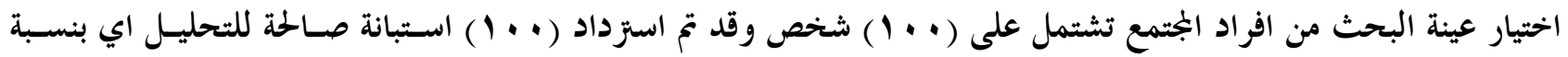

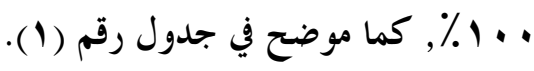




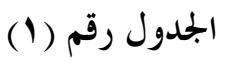

عينة الدراسة

\begin{tabular}{|c|c|c|}
\hline 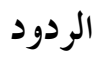 & 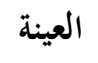 & المؤسسة \\
\hline$r \cdot$ & r. & مديرية خزينة كرميان \\
\hline 1. & 1. & بنك كلار \\
\hline 1. & 1. & بنك شيروانة \\
\hline$\varepsilon$ & $\varepsilon$ & مديرية ضريبة دخل كرميان \\
\hline 7 & 7 & مديرية ضريبة عقار كرميان \\
\hline 0 & 0 & مديرية تقاعد كرميان \\
\hline r. & r. & جامعة كرميان \\
\hline 10 & 10 & المعهد التقني كلار \\
\hline $1 \ldots$ & $1 \cdots$ & الجموع \\
\hline
\end{tabular}

ثالثاً: خصائص عينة البحث:

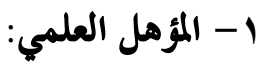

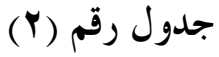

توزيع عينة البحث حسب المؤهل العلمي

\begin{tabular}{|c|c|c|}
\hline النسبة المؤية \% & تكرار & المؤهل العلمي \\
\hline$\% 1$ & 1 & دكتوراه \\
\hline$\% 0$ & 0 & ماجستير \\
\hline$\% 10$ & 10 & بكالوريوس \\
\hline$\% 70$ & 70 & 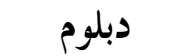 \\
\hline$\% 1 \varepsilon$ & $1 \varepsilon$ & اخرى \\
\hline$\% 1 \ldots$ & $1 \ldots$ & الجموع ع \\
\hline
\end{tabular}

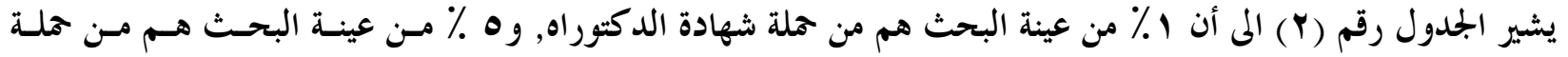

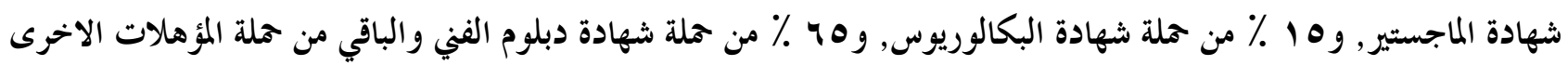
مما يدل على ارتفاع حملة المؤهلات العلمية لدى افراد عينة البحث وهذا يعزز قدرتهم على انجاز اعمالهم بكفاءة. 
جدول رقم (T)

توزيع عينة البحث حسب التخصص

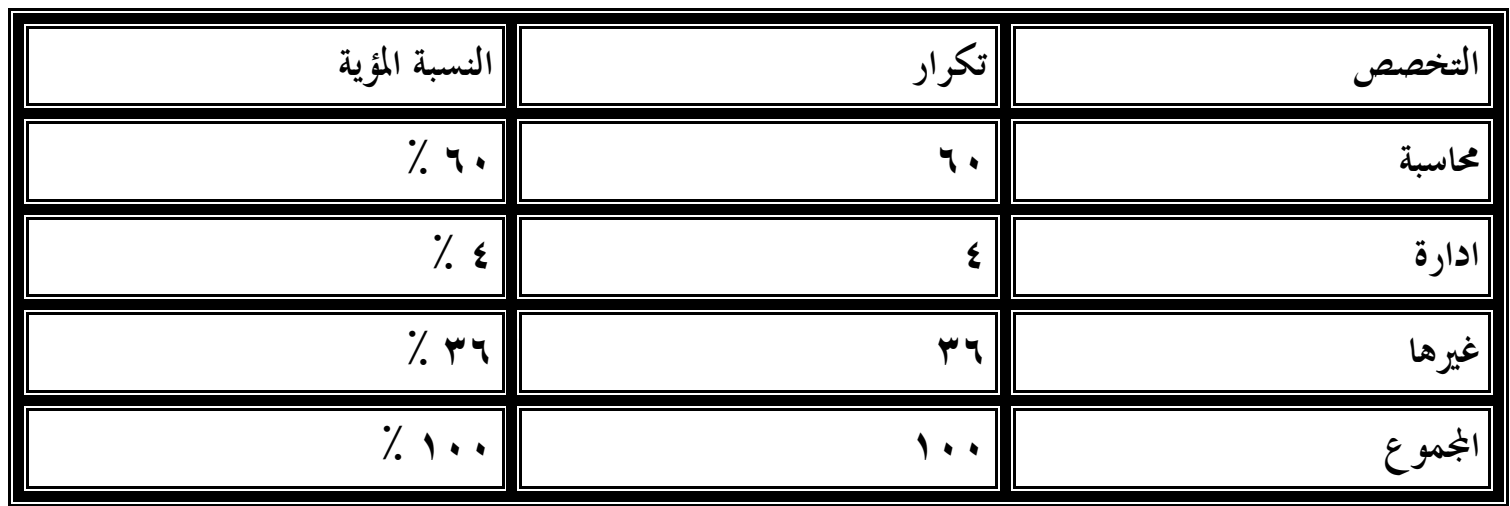

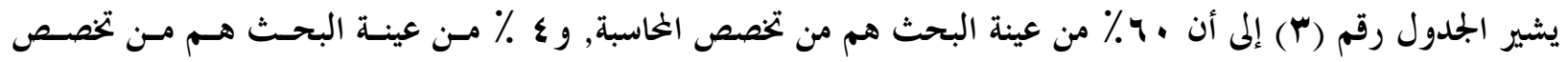

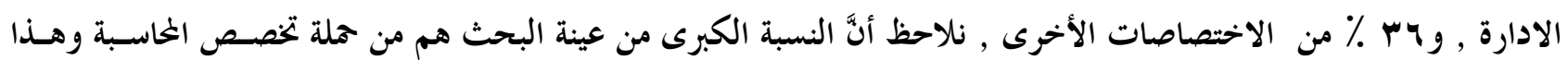
يسهم في تعزيز دقة الاجابة عن اسئلة البحث.

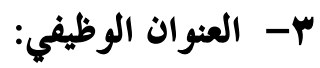
جدول رقم (飞) توزيع عينة البحث حسب عنوان الوظيفي

\begin{tabular}{|c|c|c|}
\hline النسبة المؤية & تكرار & العنوان الوظيفي \\
\hline$\%$ iv & IV & معاون محاسب \\
\hline$\% \varepsilon r$ & $\varepsilon r$ & محاسب \\
\hline$\% r$ & $r$ & مدير الحسابات \\
\hline$\% r$ & r & مدير حسابات اقدم \\
\hline$\%$ & $\mu$ & مدقق \\
\hline \% & ع & غيرها \\
\hline$\% 1 \cdot$ & $1 \cdots$ & مجموع \\
\hline
\end{tabular}

يشير الجدول رقم (ع) إلى أنَّ النسبة الكبرى من عينة البحث, وبنسبة ب ع \% هم من الخحبين, و IV \% من عينة البحث هم مـن

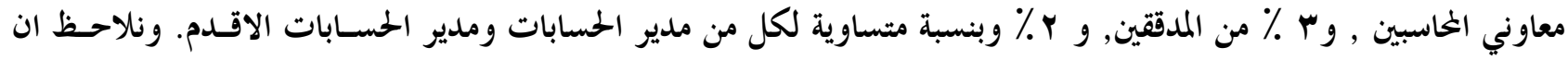
النسبة الكبر من عينة البحث هم من الخحاسبين وهذا يسهم في تعزيز دقة الاجابة عن اسئلة البحث. 


\section{ع- طبيعة سنوات الحبرة:}

\begin{tabular}{|c|c|c|}
\hline \multicolumn{3}{|c|}{ توزيع عينة البحث حسب رقم (•) } \\
\hline النسبة المئوية & تكرار & سنوات الحخبرة \\
\hline$\% \varepsilon$. & $\varepsilon$. & أقل من ه سنوات \\
\hline$\% r v$ & $r v$ & ه- - ، 1 سنوات \\
\hline ) & سץ & اكثر من · 1 سنوات \\
\hline$\% 1 \ldots$ & $1 \ldots$ & مجموع \\
\hline
\end{tabular}

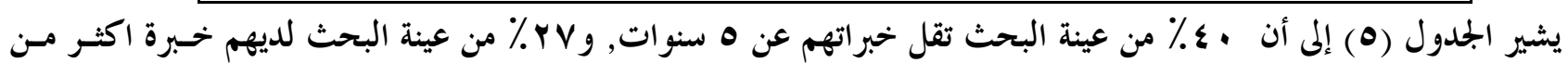
خمس سنوات, اما باقي عينة البحث فتزيد خبرتهم عن • 1 سنوات, مما يدل على أن النسبة اكبر من عينة البحث تقـل خسبرتهم

$$
\text { •- التحليل الاحصائي: }
$$

تم اعداد استبانة كأداة لتحقيق اهداف البحث, وتقسم الاستبانة المى قسـمين رئيسـين, الاول: معلومـات عامـة عـن عينـة البحث, و الثاني: معلومات خاصة بالبحث تتكون من اسئلة تغطي فقر اتها محاور البحث.

$$
\text { وفيما يلي جدول يوضح الفقرات التي تقيس متغيرات البحث: }
$$

جدول رقم (7)

\begin{tabular}{|c|c|c|}
\hline الفقرات & الخور & الفرضية \\
\hline $11-1$ & الاول & الاولى \\
\hline$r \cdot-1 r$ & الثانى & الثانية \\
\hline
\end{tabular}

قياس متغيرات البحث من خلال فقر ات الاستبانة

وقد تم الاعتماد على مقياس الخماسي لقياس متغيرات البحث اذ تم اعطاء الاوزان التالية لمقياس البحث كما يلي:

$$
\text { جدول رقم (V) }
$$

\begin{tabular}{|c|c|c|c|c|}
\hline اتفق تماما & اتفق & محايد & لا اتفق & لا اتفق اطلاقا \\
\hline 0 & $\varepsilon$ & $\mu$ & $r$ & 1 \\
\hline
\end{tabular}

المقياس المستخدم في البحث 
• اختبار الصدق: يقصد بصدق الاستبانة أن تقيس أسئلة الاستبانة ما وضعت لقياسه' , كما يقصد بالصدق "شمول الاستبانة لكل العناصر التي يجب أن تدخل في التحليل من ناحية', ووضوح فقراتها ومفرداتها من ناحية ثانية, بحيث تكون مفهومة لكل من يستخدمها.

وقد تم التأكد من صدق الاستبانة بطريقة عرض الاستبانة على مجموعة من الخكمين مؤلفة من (بّ) متخصصين في الخحاسبة والاقتصاد و الادارة من ذوي الحخبرة والكفاءة, وذلك للاستزشاد بآرائهم في مدى مناسبة الاستبانة للهدف منها, و كذلك للتأكد من صحة الصياغة ووضوحها, وقد استجاب الباحثون لآراء الغكمين, وبذلك خرج الاستبيان في صورته النهائية. - مثبار الببات:

يقصد بثبات الاستبانة أن تعطي هذه الإستبانة النتيجة نفسها لو تم إعادتها أكثر من مرة تحت نفس الظروف والشروط,

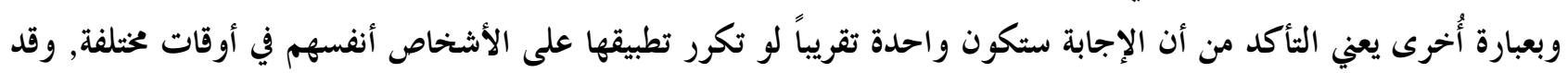
أجرى الباحثون خطوة الثبات على العينة الاستطلاعية نفسها وذلك من خلال استخدام طريقة ألفا كرونباخ.

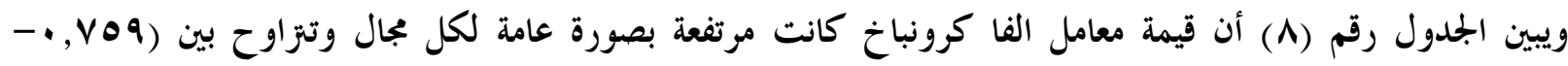
צN, • • ) لكل مجال من مجالات الاستبانة, كما كانت قيمة معامل ألفا كرونباخ لجميع فقرات الاستبانة (VA, • ), وهذا يعني أن معامل الثبات مرتفع, وبذلك تكون الاستبانة في صورتها النهائية, وبذلك يكون الباحثون قد تأكدوا من صدق وثبات الاستبانة مما يجعلهم على ثقة تامة بصحة الاستبانة وصلاحيتها للتحليل والإجابة على أسئلة البحث واختبار فرضياتها. جدول رقم (^) اختبار الصدق والثبات

\begin{tabular}{|c|c|}
\hline قيمة ه ٪ & الفقر ات \\
\hline$\cdot, \vee \wedge$ & فقر ات مجتمعة \\
\hline
\end{tabular}

- V - المعالجات الإحصائية المستخدمة في البحث:

بغية تسهيل عملية التحليل, وعقب التحصيل النهائي لاستمارات الاستبيان, قام الباحثون بتجميع البيانات الخصلة وتفريغها

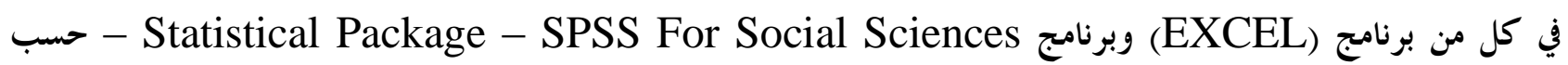
طبيعة المعلومة. وفيما يخص جمع وتبويب المعلومات التي تخص عينة البحث, فقد تم إعداد مجموعة من الجحدوال التي تم استخلاصها بالاعتماد على برنامج (EXCEL 2007), و بالبرنامج نفسه تم تثثيل تلك الجداول في أشكال تعطي وضوحاً أكثر وتسهل عمليتي الملاحظة و التحليل.

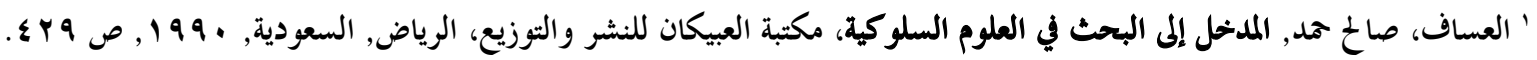

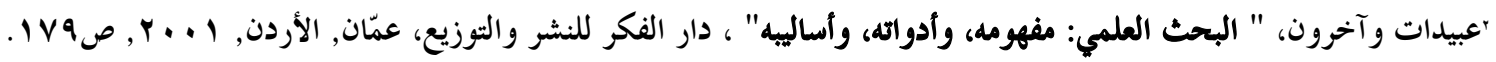


بالنسبة لجالات الاستبيان, فقد تم تجميع وتبويب إجابات أفراد العينة في برنامج (SPSS) الذي يتيح جملة من الأساليب الإحصائية المساعدة على التحليل الجيد والموضوعي لمخرجات الاستبيان, ومن بين هذه الاساليب : التكرارات, والنسب المئوية,

$$
\text { والمتوسطات الحسابية, والانخر افات المعيارية. }
$$

رابعا: التحليل الوصفي للمتغيرات البحث واختبار الفرضيات:

السؤال الأول: على صلة بالفرضية الأولى ونصها لا تتوفر شروط الاستقلالية والموضوعية للمدقى الداخلي في إقليم كردستان

\section{من وجهة نظر الفئات المشمولة.}

السؤال الثاني: على صلة بالفرضية الثانية ونصها لا توجد معوقات لتوفيز شروط استقلالية المدقى الداخلي في اقليم كردستان. استخراج الوسط الحسابي والانحراف المعياري لجميع الفقرات:

$$
\text { جدول رقم (9) }
$$

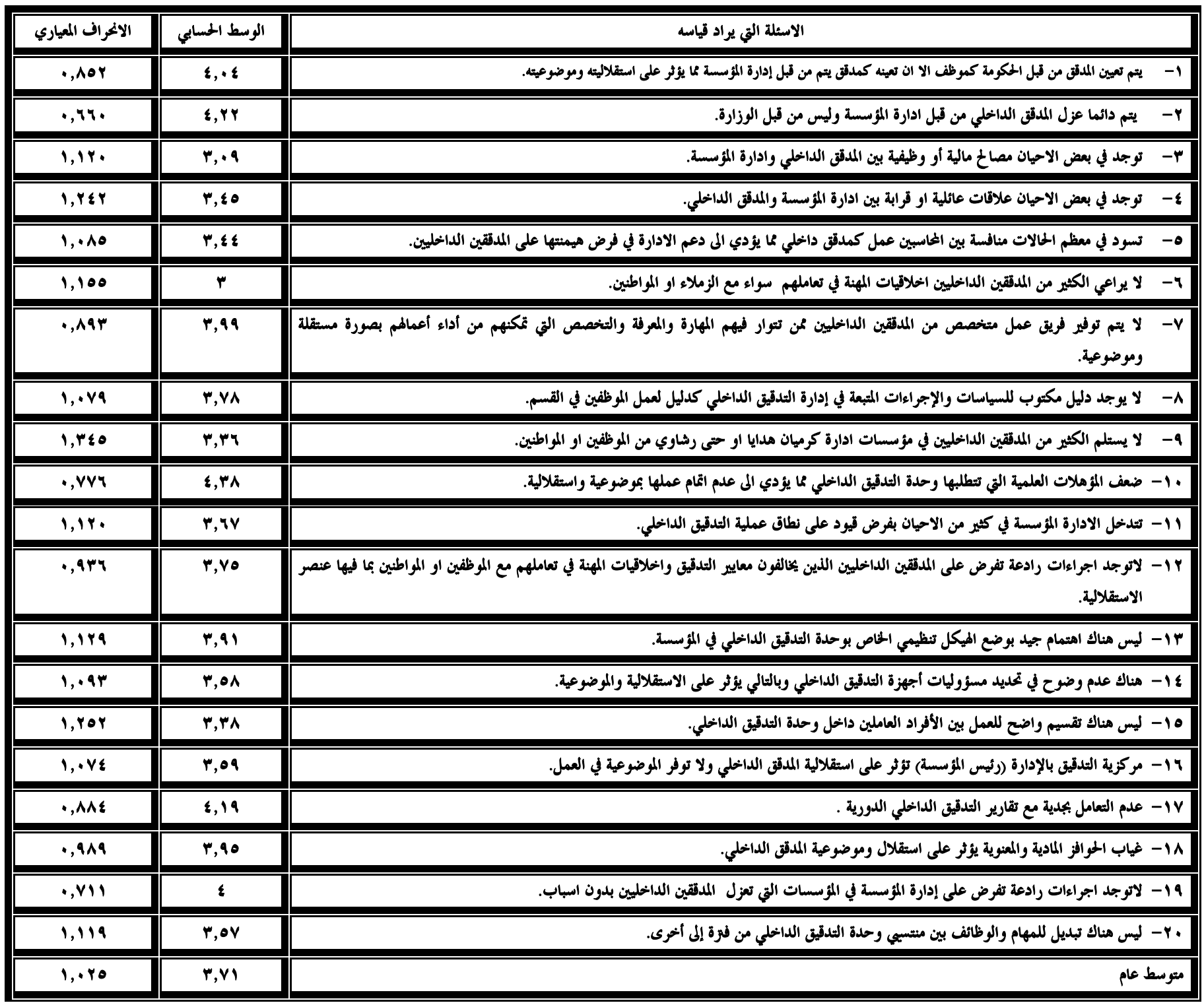


من الجحدول رقم (9), يلاحظ أن الاتجاه العام لعينة البحث يتمركز حول الموافقة على أكثرية الأسئلة التي تصب في خحانة

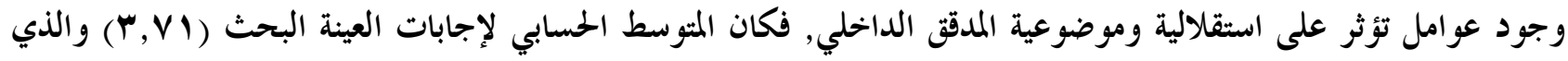

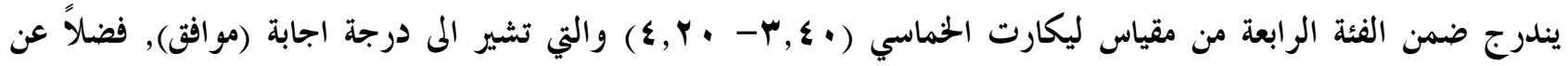
الاخر اف المعياري (ه ץ • , 1) وهي قيمة لا بأس بها ترجع لتجانس وتو افق الإجابات مما يدل على رضى غالبية أفراد العينة.

ومن جدول رقم (9) نرى ان غالبية أفراد البحث مع الفقرة (• (1) والمتعلقة بضعف المؤهلات العلمية التي تتطلبها وحدة التدقيق الداخلي مما يؤدي المى عدم اتمام عملها بموضوعية واستقلالية. وهي أكثر الفقرات موافتة من قبل الافراد العينة بمتوسط

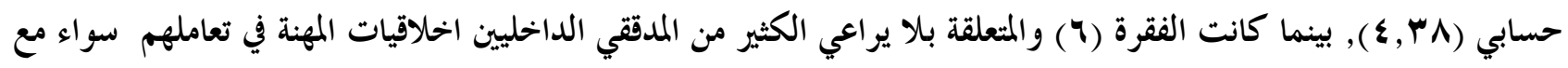
الزملاء او المواطنين هي اقل الفقرات مو افقة بمتوسط حسابي ( • (ب).

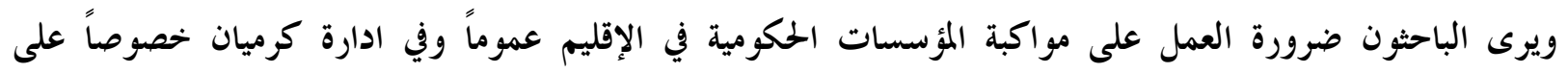
استقلالية وموضوعية وحدة التدقيق الداخلي من خحلال الدورات والندوات الخاصة بالمعايير المهنية للتدقيق الداخلي, لان الاستقلالية والموضوعية تعتبر من ركائز المهمة لعمل المهني في وحدة التدقيق الداخلي وللمدقق نفسه, كما ويجب على المؤسسات الحكومية في الاقليم بصورة العامة وفي ادارة كرميان بصورة خاصة اعادة النظر فيما يخص تعيين المدقق وعزله وهذا ما يمكن ملاحظته من اهتمام عينة البحث بالسؤال الاول والثاني وبمتوسط الحسابي (T) (1, ع), وينبغي على المؤسسات الحكومية بشكل عام وادارة كرميان بشكل خاص ان يقوموا بوضع نظام قوي رقابة الداخلية لتجنب وجود أية مصالح مالية و وظيفية أو عائلية

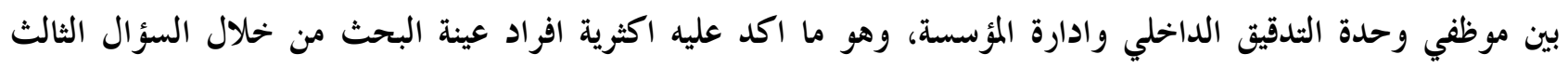

$$
\text { والسؤال الرابع وبمتوسط حسابي (r, rV (r). }
$$

كما ويجب العمل بالمعايير المهنية لتلدقيق الداخلي أو على الأقل وضع معايير أو شروط خاصة كالامثحان وسنوات الخبرة والتخصص عند اختيار المدقق الداخلي، وهذا ما يمكن ملاحظته عند اجابات افراد العينة من خحلال السؤال الخامس وبمتوسط

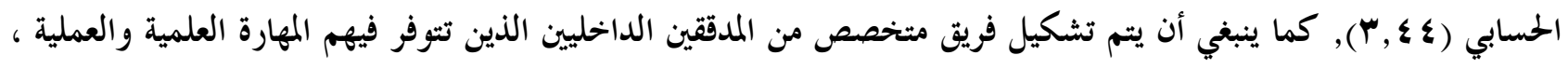
التي تمكنهم من أداء عملهم بصورة صحيحة ومرضية إلا أنه وكما يظهر من خلال إجابات أفراد عينة البحث أن أكثرية الموظفين تقريبا و بنسبة (• ع٪) من افراد العينة البحث ليسوا متخصصين, وبالتالي فإن هذا الأمر سوف تؤثر على استقلالية وموضوعية وحدة التدقيق الداخلي في المؤسسات الحكومية بشكل عام وادارة كرميان بشكل خاص, وهذا ما يؤ كده اهتمام آراء أفراد عينة

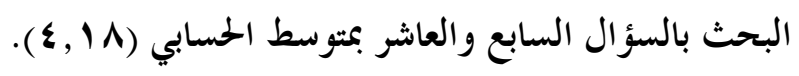
إن عدم وجود دليل مكتوب للسياسات والإجراءات المتبعة في إدارة أو وحدة التدقيق الداخلي كدليل لعمل الموظفين في القسم يؤدي إلى عدم توفر شروط الاستقلالية والموضوعية في المؤسسات الحكومية عموماً وادارة كرميان خصوصاً للتطورات الحاصلة في مهام التدقيق الداخلي, أذ أن أكثرية اجابات أفراد العينة وبمتوسط حسابي (r,VA) من خلال السؤال الثامن, تؤيد أنه لا يوجد هناك دليل مكتوب للسياسات والإجراءات. إن تدخل الادارة المؤسسة في كثير من الاحيان بفرض قيود على نطاق عملية التدقيق الداخلي وعدم اهتمامها بوضع الحما الهيكل التظيمي الخاص بوحدة التدقيق الداخلي وعدم التعامل بجدية مع التقارير الدورية لوحدة التدقيق الداخلي تؤثر على لئى 
استقلالية وموضوعية وحدة التدقيق الداخلي من خلال وجود المعوقات يحول دون اتمام عملية التدقيق بصورة مستقلة

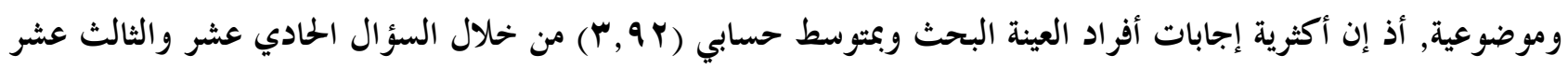
والسابع عشر.

إن عدم الوضوح في تحديد المسؤوليات وعدم تقسيم واضح للعمل بين الأفراد العاملين في وحدة التدقيق الداخلي وغياب

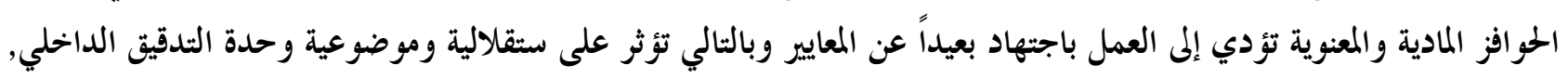

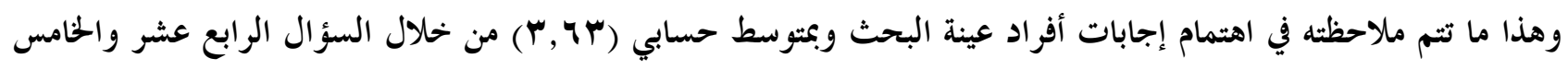
عشر و الثامن عشر.

كما إنّ مركزية وحدة التدقيق الداخلي بالادارة (رئيس المؤسسة) وعدم دوران أو تبديل للمهام والوظائف من فترة إلى

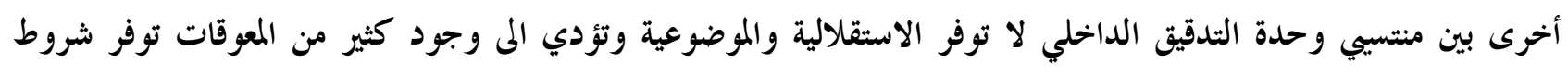

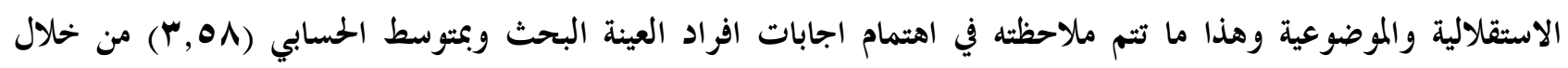
السؤال الثامن عشر والسؤال عشرين.

وامتنعت غالبية افراد عينة البحث عن الإجابة على السؤال السادس, وقد يعود سبب ذلك المى انهم ليسوا متفقين مع الباحثين في ان كثير من المدققين الداخليين لا يراعون اخلاقيات المهنة في تعاملهم سواء مع زملاء أو الموظفين او المواطيني, لذا لذا كانت أكثرية إجاباتهم محايدة وهذا ما تتم ملاحظثه في اهتمام اجابات افراد عينة البحث وبمتوسط حسابي (بّ) من خلال السؤال السادس. 


\section{المبحث الرابع: (1) \\ الاستثتاجات والثوصيات}

أولاً: الاستثاجات:

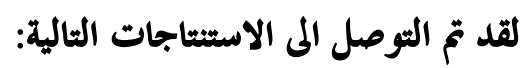

1- اظهرت نتائج البحث ان غالبية افراد عينة البحث اكدو على انه لا تتوفر شروط الاستقلالية والموضوعية للمدقق الداخلي مع وجود معوقات لتوفير شروط الاستقلالية والموضوعية.

ץ- اظهرت نتائج البحث أن غالبية أفراد عينة البحث قد اكدوا على ان تعيين وعزل المدقق الداخلي يتم من قبل ادارة المؤسسة وليس من قبل هيئة أعلى منها وهذا يؤثر على استقلاليعة وموضوعية. ب- توجد في بعض الأحيان مصاح مالية أو وظيفية او علاقات عائلية بين المدقق الداخلي وإدارة المؤسسة وبالتالي يؤثر على سيه استقلاليته وموضوعيته.

ع- لا يتم توفير فريق عمل متخصص من المدققين الداخليين ممن يتوفر فيهم المهارة والمعرفة والتخصص التي تمكهم من أداء

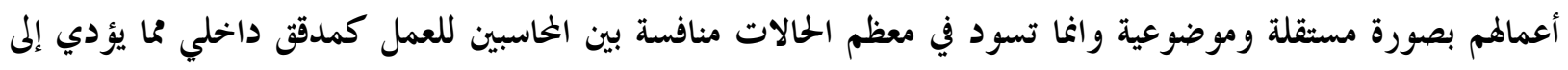
دعم إلادارة في فرض هيمنتها عليهم.

ثانياً:التوصيات:

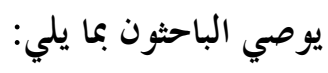
1- ضرورة العمل على ان يكون المدقق الداخلي مستقلاً وموضوعياً من خلال تنظيم دورات وندوات مختصة بمعايير الثدقيق الداخلي الخاصة بالاستقلالية والموضوعية. ץ- العمل على ان يتم تعيين المدقق الداخلي وعزله من قبل هيئة أعلى مرتبة من المدير المؤسسة بناء على الكفاءات, والاهتمام

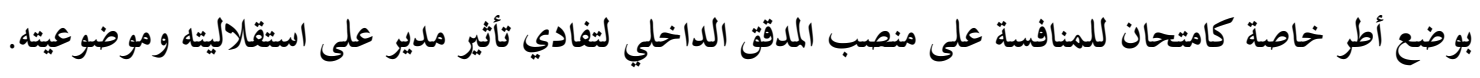
ب- العمل على توفير فريق عمل متخصص من المدققين الداخليين من تتوفر فيهم المهارة والمعرفة والتخصص التي تمكنهم من أداء أعمالفم بصورة مستقلة وموضوعية.

ع - العمل على فهرسة دليل مكتوب للسياسات والإجراءات المتبعة في إدارة التدقيق الداخلي كدليل لعمل الموظفين في القسم. أولاهتمام الجيد بوضع هيكل تنظيمي خاص بوحدة التدقيق الداخلي في المؤسسة. ه- إجبار إدارات المؤسسات على عدم فرض قيود على نطاق عملية التدقيق والتعامل بجدية مع تقارير التدقيق الداخلي الدورية. ج- الاهتمام بتبديل للمهام والوظائف بين منتسيي وحدة التدقيق الداخلي بين مدة و أخرى . 


\section{قائمة المصادر والمراجع}

القوانين والوثائق الرسمية وأدلة التدقيق:

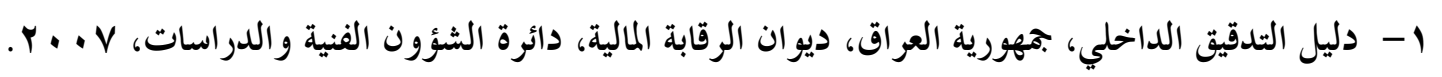

الكتب:

1- خالد راغب الحطيب, المفاهيم الحديثة في الرقابة المالية والداخلية في القطاع العام والحخاص, طا, مكتبة الخمع العربي للنشر,

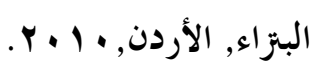

r- خلف عبداللة الواردات, الثدقيق الداخلي بين النظرية والتطبيق وفقاً لمعايير الثدقيق الداخلي الدولية, طا, مؤسسة الوراق للنشر

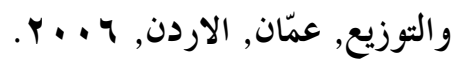

ץ- داوود يو سف صبح, دليل التدقيق الداخلي وفق المعايير الدولية, طץ, اتحاد المصارف العربية, بيروت, لبنان, • ب +r.

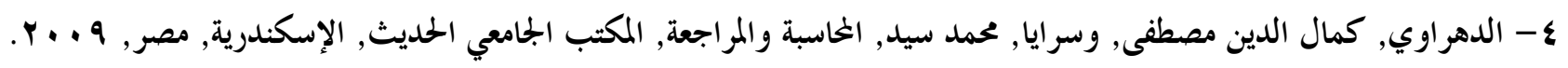

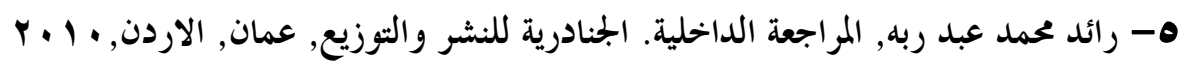

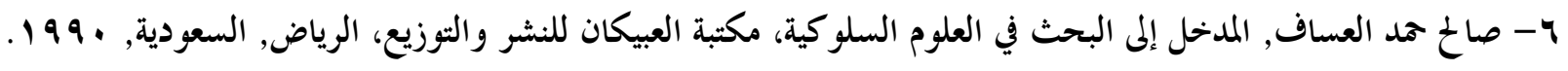

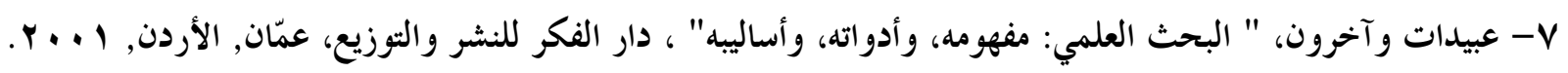

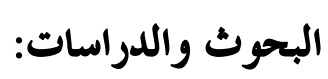
1- أحمد محمد غنيم الرشيدي, مدى توافر شروط استقلالية لمدققي الحسابات الخارجيين, جامعة الشرق الاوسط, رسالة ماجستير,

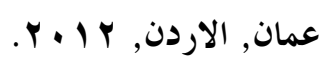

ץ- أمد محمد مخلوف, المراجعة الداخلية في ظل المعايير الدولية للتدقيق الداخلي, رسالة ماجستير , جامعة الجزائر , الجزائر..V....

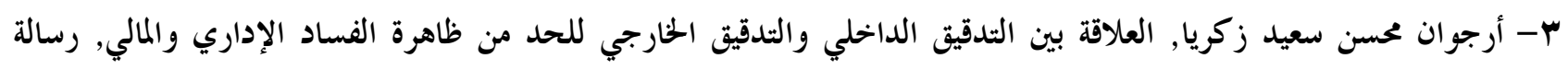

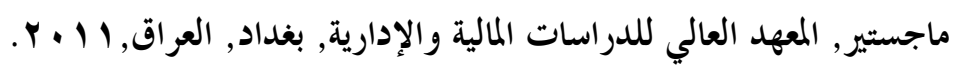
ع - اسر زاء زهير بدر, العلاقة بين الثدقيق الداخلي والثدقيق الحارجي,رسالة ماجستر المعهد العالي للدراسات المالية والادارية, بغداد,

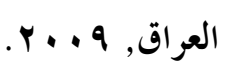

ه- فاتن خليل مجيد الأوسي, دور معايير التدقيق الداخلي في رفع كفاية أعمال التدقيق الداخلي, رسالة ماجستير, المعهد العالي

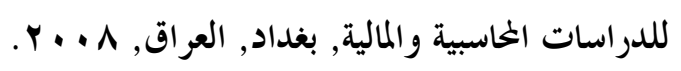

צ- فاطمة صاح مهدي غربان, مشكلات التدقيق الداخلي في القطاع التعليمي,رسالة الماجستير, جامعة المستنصرية, بغداد,العراق $. r . . r$

V- عبد الزهرة خضر حيدر الساعدي, دور الرقابة والثدقيق الداخلي للحد من ظاهرة الفساد الاداري في مسشفيات, رسالة

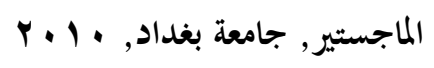




$$
\begin{aligned}
& \text { الملحق رقم (1) } \\
& \text { استمارة الاستبيان } \\
& \text { حضرة السيد الجيب الغحترم ... } \\
& \text { يقوم الباحثون بإجراء بحث بعنوان: (العوامل }
\end{aligned}
$$

المؤثرة على استقلالية وموضوعية التدقيق الداخلي-دراسة ميدانية في المؤسسات الحكومية لإدارة كَرميان). إن تقديمكم للمعلومات المطلوبة سوف يؤدي إلى مساعدة الباحثين فى تحقيق أهداف البحث واستخلاص نتائج أفضل وأكثر فائدة، لذا نرجو التكرم بالإجابة على أسئلة الاستبانة بدقة وعناية، علما أن البيانات التى ستوفرها الاستبانة تستخدم لأغراض البحث العلمى وستعامل بسرية تامة. شاكرين لكم حسن تعاونكم وتفضلوا بقبول فائق الاحتزام والتقدير

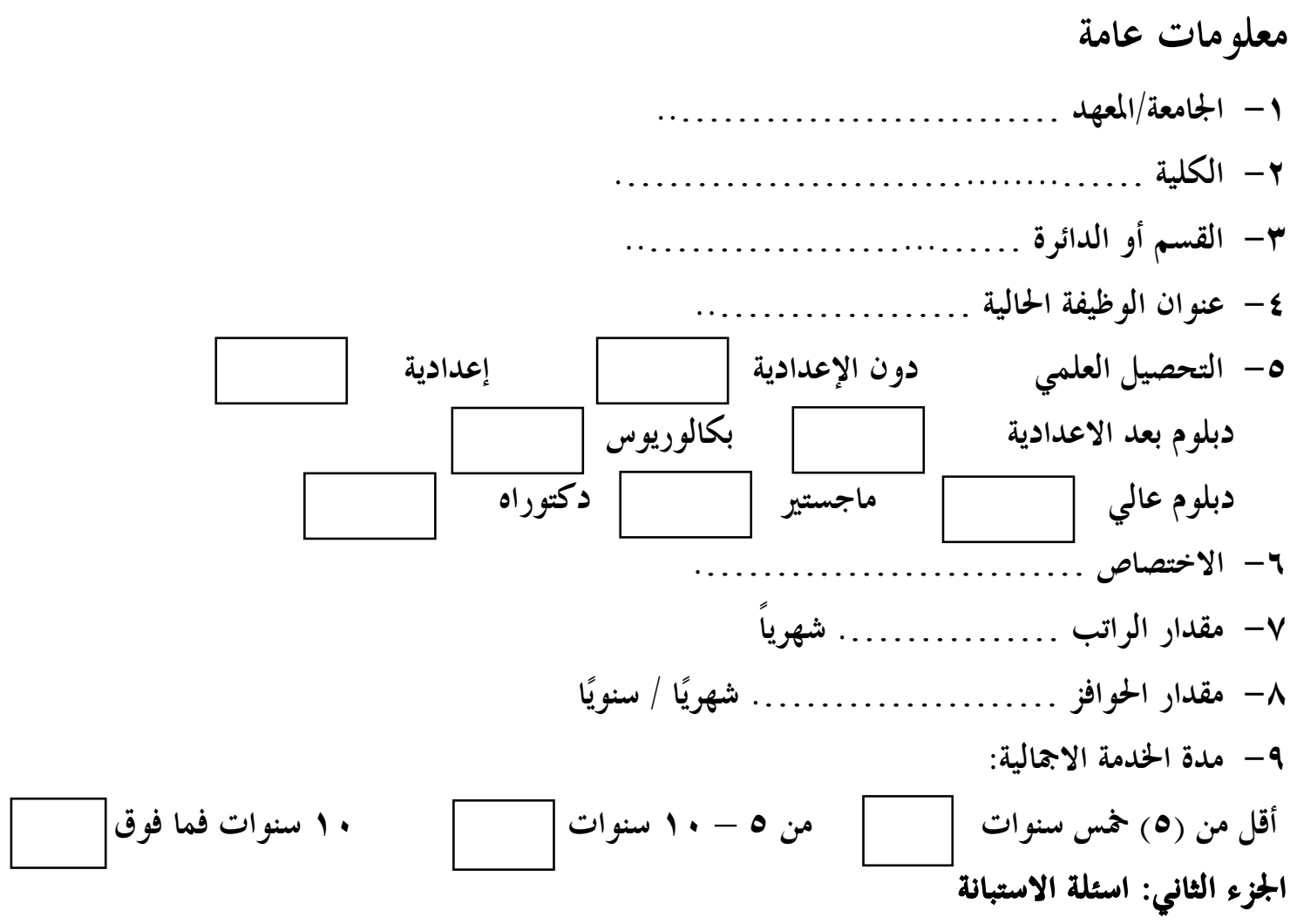

السؤال الاول: على صلة بالفرضية الاولى ونصها لا تتوفر شروط الاستقلالية والموضوعية للمدقق الداخلي في إقلسيم كردستان

من وجهة نظر الفئات المشمولة. السؤال الثاني: على صلة بالفرضية الثانية ونصها لا توجد معوقات لثوفير شروط استقلالية المدقق الداخلي في اقليم كردستان. وفيما يلي بعض المؤشرات التي تؤيد ذلك فيرجى ابداء مدى موافقتك على كل منها: 


\begin{tabular}{|c|c|c|c|c|c|}
\hline \multicolumn{5}{|c|}{ 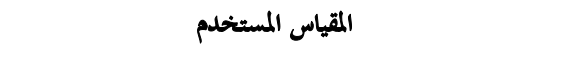 } & \multirow[b]{2}{*}{ 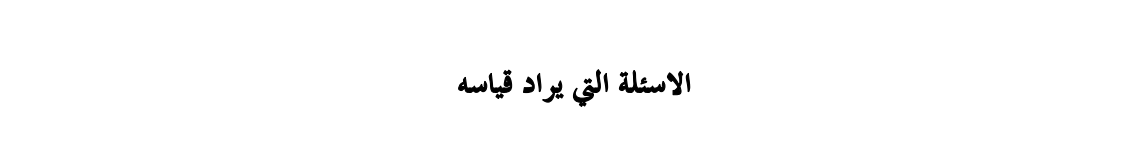 } \\
\hline لا أتفق إطلاقً & لا أتق & عحايد & أتفق & تأماً & \\
\hline & & & & & ا- - يتم تعيين المدقق في وحدة الثدقيق الداخلي من قبل المكومة كموظف الا ان تعينه كمدقق يتم من قبل \\
\hline & & & & & ץ- يتم داثما عزل المدقق في وحدة الثدقيق الداخلي من قبل ادارة المؤسسة وليس من قبل الوزارة. \\
\hline & & & & & r- توجد في بعض الأحيان مصاح مالية أو وظيفية بين الددقيق الداخلي وإدارة المؤسسة. \\
\hline & & & & & ع- توجد في بعض الاحيان علاقات عائلية او قرابة بين ادارة المؤسسة وموظفي وحدة الثدقيق الداخلي. \\
\hline & & & & & •- د- سود في معظم الحالات منافسة بين الخاسبين لعمل كمدقق في وحدة التدقيق الداخلي مما يؤدي ذلك إلى \\
\hline & & & & & צ- لا يراعي الكثير من المدققي العاملين في وحدة التدقيق الداخلي اخلاقيات المهنة في تعاملهم سواء مع ألماء المعين. \\
\hline & & & & & 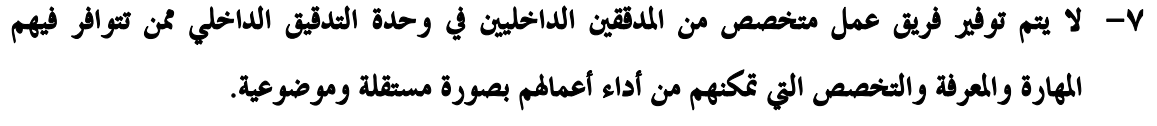 \\
\hline & & & & & ג- لا يوجد دليل مكتوب للسياسات والإجراءات المبعة في إدارة الثدقيق الداخلي كدليل لعمل الموظفين في \\
\hline & & & & & q- ح- لا يستلم الكثي من المدققين الداخليين في وحدة الثدقيق الداخلي في مؤسسات ادارة كرميان هدايا او \\
\hline & & & & & • 1- ضعف المؤهلات العلمية التي تتطلبها وحدة التدقيق الداخلي مما يؤدي المى عدم اتمام عملها بموضوعية \\
\hline & & & & & 11-تتدخل الادارة المؤسسة في كثير من الاحيان بفرض قيود على نطاق عملية التدقيق الداخلي. \\
\hline & & & & & با الاتوجد اجراءات رادعة تفرض على المدققين الداخليين في وحدة الثدقيق الداخلي الذين يخالفون معايير \\
\hline & & & & & با ا-ليس مناك اهتمام جيد بوضع الميكل تنظيمي الحماص بوحدة التدقيق الداخلي في المؤسسة. \\
\hline & & & & & ع ا-مناك عدم وضوح في تحديد مسؤليات أجهزة الثدقيق الداخلي وبالتالي يؤثر على الاستقلالية \\
\hline & & & & & 10 ا-ليس مناك تقسيم واضح للعمل بين الأفراد العاملين داخل وحدة الثدقيق الداخلي. \\
\hline
\end{tabular}




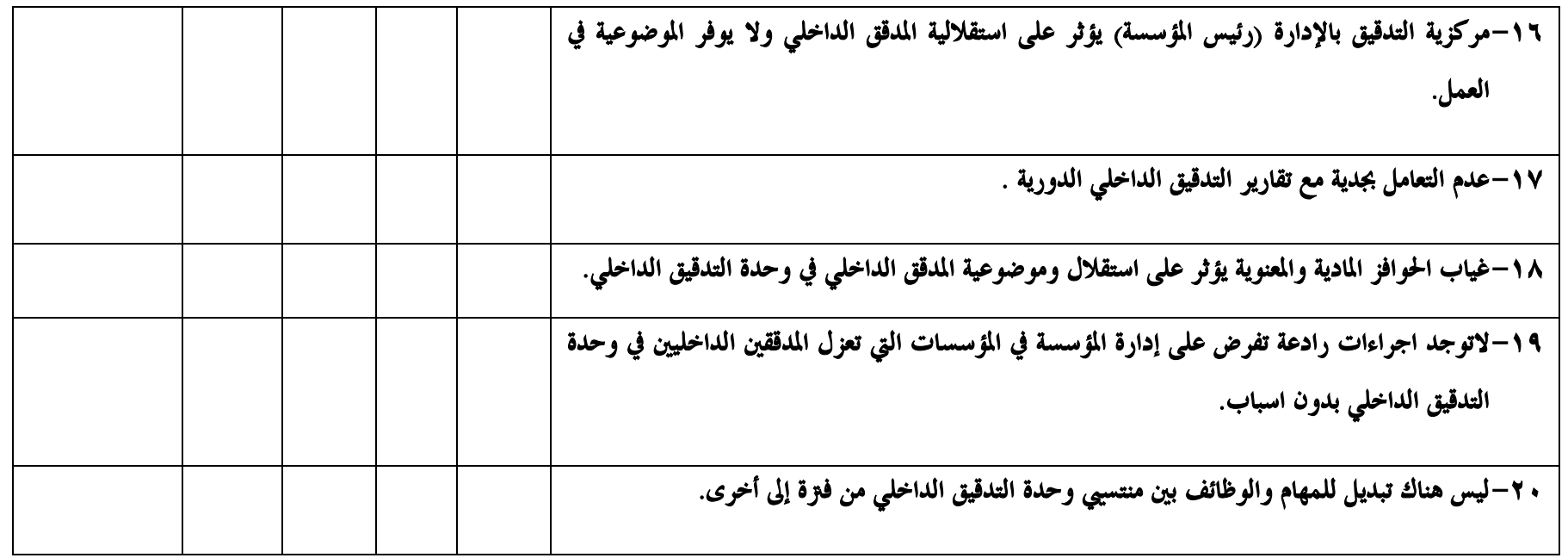

